\title{
Structural elucidation and antimicrobial activity of new phencomycin derivatives isolated from Burkholderia glumae strain 411gr-6
}

\author{
Jae-Woo Han ${ }^{1}$, Jeong-Do Kim ${ }^{1}$, Jung-Min Lee ${ }^{1}$, Jong-Hyun Ham ${ }^{2}$, Dongho Lee ${ }^{1}$ and Beom-Seok Kim ${ }^{1}$
}

The Journal of Antibiotics (2014) 67, 721-723; doi:10.1038/ja.2014.50; published online 30 April 2014

Burkholderia spp. isolates have been reported to produce antimicrobial compounds, including pyrrolnitrin, pyoluteorin and phenazine compounds. ${ }^{1-3}$ Phenazines are colored antimicrobial metabolites that exhibit broad-spectrum antimicrobial activity against bacteria, yeast and filamentous fungi. They comprise a large group of nitrogencontaining heterocyclic compounds with different chemical and physical properties dependent upon the type and position of the functional groups present. ${ }^{4}$ In the course of our investigation on the antimicrobial pigments produced by Burkholderia glumae strain 411 gr- $6,{ }^{5}$ we identified phencomycin ${ }^{6}$ (a phenazine with two substituents, a carboxyl and a carbomethoxy group; Figure 1) and its new derivatives. Here, we report the purification, structural elucidation and antimicrobial properties of 4-hydroxyphencomycin (1) and 5,10-dihydro-4,9-dihydroxyphencomycin methyl ester (2; Figure 2).

B. glumae strain $411 \mathrm{gr}-6$ was cross-hatch streaked on $2 \mathrm{~kg}$ casamino acid-peptone-glucose (CPG; casamino acid $1 \mathrm{~g}$, peptone $10 \mathrm{~g}$, glucose $10 \mathrm{~g}$ and agar $18 \mathrm{~g}$, in $1 \mathrm{~L}$ distilled water) agar medium and incubated at $28^{\circ} \mathrm{C}$ for $3-4$ days. Bacterial cells were harvested and extracted with $2 \mathrm{~L} \mathrm{MeOH}$, which had a potent inhibitory effect on spore germination against Colletotrichum orbiculare. After concentration in vacuo, the residue $(6.0 \mathrm{~g})$ was suspended in distilled water and extracted with $\mathrm{CHCl}_{3}$. The antifungal organic layer was evaporated to dryness. The residue $(872.0 \mathrm{mg})$ was applied to Diaion HP-20 resin columns (Mitsubishi Chemical, Tokyo, Japan) and eluted from columns using stepwise gradients of aqueous $\mathrm{Me}_{2} \mathrm{CO}(0,20,40,60,80$ and $100 \%$, v/ v). The antifungal $60 \% \mathrm{Me}_{2} \mathrm{CO}$ fraction $(54.4 \mathrm{mg}$ ) was further purified using a semi-preparative Varian Prostar 210 (Palo Alto, CA, USA) HPLC system equipped with a reversed-phase C18 column (ODS-H80, $250 \times 10 \mathrm{~mm}, 4 \mu \mathrm{m}$, YMC, Kyoto, Japan). The column was eluted at a flow rate of $2 \mathrm{ml} \mathrm{min}^{-1}$ for $30 \mathrm{~min}$ using $50 \%$ aqueous $\mathrm{CH}_{3} \mathrm{CN}$ containing $0.1 \%$ formic acid. The effluent was monitored at $365 \mathrm{~nm}$. Final purification using a reversed-phase HPLC system gave phencomycin $\left(0.8 \mathrm{mg}, t_{\mathrm{R}}=13.8\right), \mathbf{1}\left(1.0 \mathrm{mg}, t_{\mathrm{R}}=11.4\right)$ and $2(2.0 \mathrm{mg}$, $\left.t_{\mathrm{R}}=18.4\right)$.
A new phencomycin derivative, 4-hydroxyphencomycin (1) was isolated as a yellow powder; $\mathrm{UV}(\mathrm{MeOH}) \lambda_{\max }(\log \varepsilon) 209$ (4.61), 270 (4.57), 370 (3.91) nm; ${ }^{1} \mathrm{H}$ NMR $\left(\mathrm{CDCl}_{3}, 500 \mathrm{MHz}\right): 14.48$ (1H, br s, 11-OH), $9.01(1 \mathrm{H}, \mathrm{d}, J=8.0, \mathrm{H}-2), 8.49(1 \mathrm{H}, \mathrm{d}, J=7.0, \mathrm{H}-7), 8.47$ $(1 \mathrm{H}, \mathrm{d}, J=8.0, \mathrm{H}-9), 8.07(1 \mathrm{H}, \mathrm{dd}, J=7.0,8.0), 7.46(1 \mathrm{H}, \mathrm{d}, J=8.0$, $\mathrm{H}-3), 4.13\left(3 \mathrm{H}, \mathrm{s}, 12-\mathrm{OCH}_{3}\right) ;{ }^{13} \mathrm{C} \mathrm{NMR}\left(\mathrm{CDCl}_{3}, 125 \mathrm{MHz}\right): 165.7$ (C-11), 165.5 (C-12), 156.7 (C-4), 141.5 (C-2), 140.7 (C-9a and C-10a, overlapped signals), 139.0 (C-5a), 134.4 (C-4a and C-7, overlapped signals), 132.4 (C-9), 132.2 (C-8), 130.5 (C-6), 115.9 (C-1), 110.3 (C-3), $53.1\left(12-\mathrm{OCH}_{3}\right)$. HR-ESI-MS analysis identified an $[\mathrm{M}+\mathrm{H}]^{+}$ion at $m / z 299.0675$ (calcd $m / z: 299.0668$ ), consistent with a molecular formula of $\mathrm{C}_{15} \mathrm{H}_{10} \mathrm{~N}_{2} \mathrm{O}_{5}$, one more oxygen than phencomycin. ${ }^{6}$ The 12 degrees of unsaturation, implied by the molecular formula and UV absorbance spectrum, were accounted for a phenazine ring substituted by two carbonyl groups. The ${ }^{13} \mathrm{C}$ NMR spectrum of 1 showed resonances for only 13 carbon atoms, because of the overlapped carbon signals at $\delta 134.4$ and $140.7 .{ }^{1} \mathrm{H}$ NMR spectrum of 1 suggested that the three substituents, including a hydroxyl, carboxyl and carbomethoxy group, could be present at 1, 4 and 6, or 1, 6 and 9 positions. The substituents and their location on the phenazine ring were determined by analysis of the ${ }^{1} \mathrm{H}-{ }^{1} \mathrm{H}$ COSY and HMBC spectra of $\mathbf{1}$ (Figure 2).

5,10-Dihydro-4,9-dihydroxyphencomycin methyl ester (2) was isolated as a yellow powder; UV $(\mathrm{MeOH}) \lambda_{\max }(\log \varepsilon) 213$ (4.34), 276 (4.78), 370 (3.65) nm; IR (ATR) $v_{\max } 3283$ (br), 2925 (br), 1644, $1534,1450,1393,1310,1252,1055,834,667,553 \mathrm{~cm}^{-1} ;{ }^{1} \mathrm{H}$ NMR $\left(\mathrm{CDCl}_{3}, 500 \mathrm{MHz}\right): 9.06(2 \mathrm{H}$, br s, NH), $8.60(2 \mathrm{H}, \mathrm{d}, J=8.0, \mathrm{H}-2$ and $\mathrm{H}-7), 7.32(2 \mathrm{H}, \mathrm{d}, J=8.0, \mathrm{H}-3$ and $\mathrm{H}-8), 4.06\left(6 \mathrm{H}, \mathrm{s}, 11-\mathrm{OCH}_{3}\right.$ and $\left.12-\mathrm{OCH}_{3}\right) ;{ }^{13} \mathrm{C} \mathrm{NMR}\left(\mathrm{CDCl}_{3}, 125 \mathrm{MHz}\right): 165.5(\mathrm{C}-11$ and $\mathrm{C}-12)$, 156.3 (C-4, C-9), 139.0 (C-5a and C-10a), 138.3 (C-2 and C-7), 134.7 (C-4a and C-9a), 118.7 (C-1 and C-6), 108.9 (C-3 and C-8), 52.2 $\left(11-\mathrm{OCH}_{3}\right.$ and $\left.12-\mathrm{OCH}_{3}\right)$. HR-ESI-MS analysis gave an $[\mathrm{M}-\mathrm{H}]^{-}$ ion at $\mathrm{m} / z 329.0768$ (calcd $\mathrm{m} / \mathrm{z}: 329.0765)$ consistent with a molecular formula of $\mathrm{C}_{16} \mathrm{H}_{14} \mathrm{~N}_{2} \mathrm{O}_{6}$, which indicated 11 degrees of unsaturation.

${ }^{1}$ Department of Biosystems and Biotechnology, College of Life Sciences and Biotechnology, Korea University, Seoul, Republic of Korea and ${ }^{2}$ Department of Plant Pathology and Crop Physiology, Louisiana State University Agricultural Center, Baton Rouge, LA, USA

Correspondence: Professor Dr B-S Kim, Department of Biosystems and Biotechnology, College of Life Sciences and Biotechnology, Korea University, Seoul 136-713, Republic of Korea. 
<smiles>COC(=O)c1cccc2nc3c(C(=O)O)cccc3nc12</smiles>

Figure 1 Structure of phencomycin.
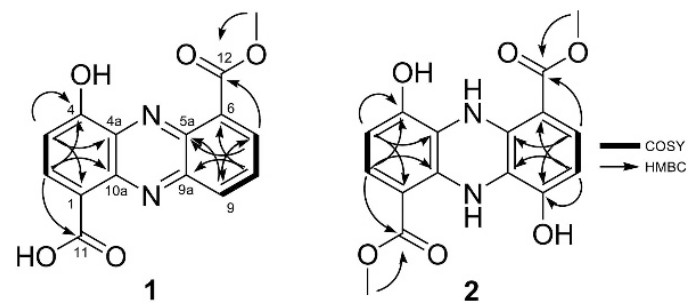

Figure 2 Structures and ${ }^{1} \mathrm{H}-{ }^{1} \mathrm{H}$ COSY and key HMBCs of 4-hydroxyphencomycin (1) and 5,10-dihydro-4,9-dihydroxyphencomycin methyl ester (2).

The ${ }^{13} \mathrm{C}$ NMR spectrum contained only eight signals, two carbomethoxy carbons and aromatic carbons including two secondary and four quaternary carbons, thus indicating that 2 must be a symmetric dimer. The ${ }^{1} \mathrm{H}$ NMR spectrum of 2 showed an NH-proton at $\delta_{\mathrm{H}} 9.06$ (br s), two adjacent aromatic protons at $\delta_{\mathrm{H}} 8.60(\mathrm{~d}, J=8.0 \mathrm{~Hz})$ and $7.32(\mathrm{~d}, J=8.0 \mathrm{~Hz})$, and one methoxy signal at $\delta_{\mathrm{H}} 4.05$. The substitution pattern of the individual benzene rings was established by COSY and HMBC (Figure 2). Based on the molecular formula, both parts must be connected by $\mathrm{NH}$ bridges forming a 5,10dihydrophenazine. ${ }^{7}$ Comparison of the NMR data of 2 with those of 4,9-dihydroxyphencomycin methyl ester, previously isolated from Burkholderia cepacia ATCC $17460,{ }^{8-10}$ revealed a high degree of similarity in the aromatic rings and substituted functional groups except for the presence of two additional identical $\mathrm{NH}$ broad singlets at $\delta_{\mathrm{H}}$ 9.06. Although antimicrobial pigments with phenazine structures have frequently been isolated from microbial cultures, $\mathrm{N}$ unsubstituted simple dihydrophenazine structures are rarely isolated from microbial metabolites. ${ }^{11}$ Notably, chlororaphin and dihydrophencomycin methyl ester were identified in cultures of Bacillus pyocyaneus and Streptomyces sp. B8251, respectively. ${ }^{11,12}$ MIC was determined (Table 1) using the Clinical and Laboratory Standards Institute (CLSI) broth micro-dilution susceptibility method (M38-A) in 96-well plates. ${ }^{13}$ Compounds were serially diluted by twofold to concentrations of $0,1,2,4,8,16,32,64$ and $128 \mu \mathrm{g} \mathrm{ml}^{-1}$. Suspensions $\left(1 \times 10^{5}\right.$ spores or mycelial fragments $\left.\mathrm{ml}^{-1}\right)$ of fungi, oomycetes were used as inocula in this test. Phencomycin exhibited weak antibacterial activity and no evident antifungal activity. Compound $\mathbf{1}$ did not show inhibitory activity against most microorganisms tested in this study, even at concentrations of $128 \mu \mathrm{g} \mathrm{ml}^{-1}$. The only exception was that $128 \mu \mathrm{g} \mathrm{ml}^{-1}$ of compound 1 inhibited the growth of Bacillus. Compound 2 displayed MICs ranging from 1 to $16 \mu \mathrm{g} \mathrm{ml}^{-1}$ against most microorganisms tested. Bacillus, Micrococcus and Ralstonia (MIC
Table 1 In vitro antimicrobial activity of phencomycin derivatives

\begin{tabular}{|c|c|c|c|}
\hline \multirow[b]{2}{*}{ Microorganism } & \multicolumn{3}{|c|}{$\operatorname{MIC}\left(\mu g m l^{-1}\right)^{\mathrm{a}}$} \\
\hline & Phencomycin & $1^{\mathrm{b}}$ & 2 \\
\hline \multicolumn{4}{|l|}{ Plant pathogenic fungi } \\
\hline Alternaria brassicicola & $>128$ & $>128$ & 2 \\
\hline Aspergillus oryzae & $>128$ & $>128$ & 16 \\
\hline Botrytis cinerea & 128 & $>128$ & 1 \\
\hline Cladosporium cucumerinum & $>128$ & $>128$ & 4 \\
\hline Colletotrichum gloeosporioides & $>128$ & $>128$ & 1 \\
\hline Colletotrichum orbiculare & 128 & $>128$ & 1 \\
\hline Cylindrocarpon destructans & $>128$ & $>128$ & 16 \\
\hline Diaporthe citri & 128 & $>128$ & 1 \\
\hline Fusarium oxysporum & $>128$ & $>128$ & 16 \\
\hline Magnaporthe oryzae & 128 & $>128$ & 2 \\
\hline Phytophthora capsici & $>128$ & $>128$ & 16 \\
\hline Rhizopus stolonifer & $>128$ & $>128$ & 16 \\
\hline Sclerotinia sclerotiorum & $>128$ & $>128$ & 16 \\
\hline \multicolumn{4}{|l|}{ Yeasts } \\
\hline Candida albicans & $>128$ & $>128$ & 2 \\
\hline Saccharomyces cerevisiae & 64 & $>128$ & 1 \\
\hline \multicolumn{4}{|l|}{ Bacteria } \\
\hline Bacillus megaterium & 128 & 128 & $>128$ \\
\hline Escherichia coli & $>128$ & $>128$ & 16 \\
\hline Micrococcus luteus & 128 & $>128$ & 128 \\
\hline Pseudomonas syringae & $>128$ & $>128$ & 16 \\
\hline Ralstonia solanacearum & $>128$ & $>128$ & 64 \\
\hline Xanthomonas campestris & 32 & $>128$ & 2 \\
\hline
\end{tabular}

aConcentration that completely inhibits the growth of target microorganism.

b4-Hydroxyphencomycin (1) and 5,10-dihydro-4,9-dihydroxyphencomycin methyl ester (2).

values at $>128,128$ and $64 \mu_{\mathrm{g} \mathrm{ml}}^{-1}$, respectively) were less sensitive to compound 2 . In conclusion, antimicrobial pigments produced by $B$. glumae strain 411 gr- 6 were purified and identified as phencomycin and its derivatives. A novel phencomycin derivative, 5,10-dihydro-4,9-dihydroxyphencomycin methyl ester displayed potent inhibitory activity against a variety of bacteria, yeasts and plant pathogenic fungi. This compound warrants further investigation and could be developed as a broad-spectrum antimicrobial agent.

\section{ACKNOWLEDGEMENTS}

This study was financially supported by the National Research Foundation of Korea (2010-0010396).

1 Hwang, J., Chilton, W. \& Benson, D. Pyrrolnitrin production by Burkholderia cepacia and biocontrol of Rhizoctonia stem rot of poinsettia. Biol. Control 25, 56-63 (2002).

2 Mavrodi, D. V., Blankenfeldt, W. \& Thomashow, L. S. Phenazine compounds in fluorescent Pseudomonas spp. biosynthesis and regulation*. Annu. Rev. Phyto. 44, 417-445 (2006).

3 Souza, J. T. \& Raaijmakers, J. M. Polymorphisms within the $p r n D$ and $p / t C$ genes from pyrrolnitrin and pyoluteorin producing Pseudomonas and Burkholderia spp. FEMS Microbiol. Ecol. 43, 21-34 (2003).

4 Price-Whelan, A., Dietrich, L. E. P. \& Newman, D. K. Rethinking 'secondary' metabolism: physiological roles for phenazine antibiotics. Nat. Chem. Biol. 2, 71-78 (2006).

5 Karki, H. S. et al. Diversities in virulence, antifungal activity, pigmentation and DNA fingerprint among strains of Burkholderia glumae. PLOS ONE 7, e45376 (2012).

6 Chatterjee, S. et al. Phencomycin, a new antibiotic from a Streptomyces species HIL Y-9031725. J. Antibiot. (Tokyo). 48, 1353 (1995).

7 Bailey, D. N., Roe, D. K. \& Hercules, D. M. Near-ultraviolet absorption spectrum of 5 , 10-dihydrophenazine. Appl. Spectrosc. 22, 785-786 (1968). 
8 Korth, H., Römer, A., Budzikiewicz, H. \& Pulverer, G. 4, 9-Dihydroxyphenazine-1, 6-dicarboxylic acid dimethylester and the 'missing link' in phenazine biosynthesis. J. Gen. Microbiol. 104, 299-303 (1978).

9 Römer, A. ${ }^{1}$ H NMR spectra of substituted phenazines. Org. Magn. Reson. 19, 66-68 (1982).

10 Römer, A. ${ }^{13} \mathrm{C}$ NMR spectra of substituted phenazines: Substituent effects on carbon-13 chemical shifts and the use of ${ }^{13} \mathrm{C}-{ }^{15} \mathrm{~N}$ coupling constants for the assignment of the aromatic carbons. Org. Magn. Reson. 21, 130-136 (1983).
11 Pusecker, K., Laatsch, H., Helmke, E. \& Weyland, H. Dihydrophencomycin methyl ester, a new phenazine derivative from a marine Streptomycete. J. Antibiot. 50, 479 (1997).

12 Birkofer, L. Chlororaphin, ein weiteres farbiges Stoffwechselprodukt des Bacillus pyocyaneus. Chem. Ber. 80, 212-214 (1947).

13 Espinel-Ingroff, A. et al. Quality control and reference guidelines for CLSI broth microdilution susceptibility method (M38-A document) for amphotericin B, itraconazole, posaconazole, and voriconazole. J. Clin. Microbiol. 43, 5243-5246 (2005). 